\title{
Perspectives on family caregiving of people aging with intellectual disability affected by dementia: Commentary from the International Summit on Intellectual Disability and Dementia $^{1 \#}$
}

Nancy Jokinen ${ }^{1}$, Tiziano Gomiero ${ }^{2}$, Karen Watchman ${ }^{3}$, Matthew P. Janicki ${ }^{4}$, Mary Hogan ${ }^{5}$, Frode Larsen $^{6}$, Anna Beránková ${ }^{\text {, Flávia Heloísa Santos }}{ }^{8,9}$, Kathy Service ${ }^{10}$, \& Jim Crowe ${ }^{11,12}$

${ }^{1}$ University of Northern British Columbia, Prince George, BC, Canada

${ }^{2}$ Project DAD ANFFAS Trentino Onlus, Trento, Italy

${ }^{3}$ University of Stirling, Scotland

${ }^{4}$ University of Illinois at Chicago, USA

${ }^{5}$ National Task Group in Intellectual Disabilities and Dementia Practices, Eliot, Maine, USA

${ }^{6}$ Norwegian National Advisory Unit on Ageing and Health, Oslo, Norway

${ }^{7}$ Charles University, Prague, Czech Republic

${ }^{8}$ São Paulo State University, Bauru, Brazil

${ }^{9}$ University of Minho, Braga, Portugal

${ }^{10}$ Nurse Practitioner Consultant, Northampton, Massachusetts, USA

${ }^{11}$ EASPD, Brussels, Belgium

${ }^{12}$ Learning Disability Wales, Cardiff, Wales

Author's correspondence address:

Nancy Jokinen, Ph.D., School of Social Work, University of Northern British Columbia, 3333 University Way, Prince George, BC Canada V2N 4Z9. Email: Nancy.Jokinen@unbc.ca

Key words: dementia, caregivers, caregiving, Down syndrome, intellectual disability, narratives Running head: Perspectives on caregiving and dementia

The authors acknowledge Dr. Liliana Mayo of the Centro Ann Sullivan del Perú- CASP in Lima, Peru for providing the Peruvian narrative.

\footnotetext{
${ }^{1 \#}$ This consensus statement was developed as an output of the 2016 International Summit on Intellectual Disability and Dementia, held in Glasgow, Scotland, 13-14 October 2016, and hosted by the University of Stirling and University of the West of Scotland, funded by the RS MacDonald Trust, the Scottish Government, and Alzheimer Scotland. Collaborating sponsors included the National Task Group on Intellectual Disabilities and Dementia Practices (NTG) in the United States and the University of Illinois at Chicago. The Summit was composed of individuals and representatives of many international and national organizations with a stake in issues related to adults with intellectual disability affected by dementia. The contents of this statement were partially developed under a grant from the United States Department of Health and Human Services, Administration for Community Living (ACL), National Institute on Disability, Independent Living, and Rehabilitation Research (NIDILRR) Grant \# 90RT5020-03-00. However, those contents do not necessarily represent the policy of the US Department of Health and Human Services, nor the endorsement by the US Federal Government. The opinions expressed represent those of the Summit participants and of the NTG
} 


\begin{abstract}
This article, an output of the 2016 International Summit on Intellectual Disability and Dementia, examines familial caregiving situations within the context of a support-staging model for adults with intellectual disability (ID) affected by dementia. Seven narratives offer context to this supportstaging model to interpret situations experienced by caregivers. The multi-dimensional model has two fundamental aspects: identifying the role and nature of caregiving as either primary (direct) or secondary (supportive); and defining how caregiving is influenced by stage of dementia. We propose staging can affect caregiving via different expressions: (1) the 'diagnostic phase', (2) the 'explorative phase', (3) the 'adaptive phase', and (4) the 'closure phase'. The international narratives illustrate direct and indirect caregiving with commonality being extent of caregiver involvement and attention to the needs of an adult with ID. We conclude that the model is the first to empirically formalise the variability of caregiving within families of people with ID that is distinct from other caregiving groups, and that many of these caregivers have idiosyncratic needs. A support-staging model that recognises the changing roles and demands of carers of people with intellectual disability and dementia can be useful in constructing research, defining family-based support services, and setting public policy.
\end{abstract}




\section{Introduction}

The WHO's report, Dementia: A Public Health Priority (World Health Organization \& Alzheimer's Disease International, 2012) recognized that adults with intellectual disabilities affected by dementia and their caregivers have needs that may mirror the needs of other caregivers in general, but at times are distinct due the lifelong nature of intellectual disability. Caregivers are individuals, related or unrelated to the adult with an intellectual disability, who are providing dementia supports and supervision, looking after the adult's interests, and involved in significant decisions about supports and care, or acting as advocates on their behalf. Studies in intellectual disability also highlight the peculiarities of family caregivers of people with intellectual disability that, after a lifetime of caring, now face new challenges when dementia presents and questions their ability to continue as caregivers (Author, 2017).

Recognizing that the provision of dementia care may vary by social values and public polices, parsing some of the differences in extant care structures can help identify how such care varies for persons with intellectual disability. In some countries, for instance, most people with intellectual disabilities live at home - usually with one or both parents, a sibling, or extended kin. In other countries, the prevailing norm is independent or supervised living in private or public accommodations with direct support needs organized by a service provider (Braddock, Hemp, \& Rizzolo, 2011; Carvalho, Ardore, \& Castro, 2015; Tøssebro et al., 2012). While caregiving may focus on the resident, families, regardless of living circumstance, often continue to play an important role supporting their aging relative with intellectual disability. These support roles often expand and become more prominent with the development of an age-associated debilitating condition, such as dementia, as dependencies become more pronounced.

In many localities, there is a growing number of older family members who continue to provide primary care for relatives with an intellectual disability well into old age. Such caregiving 
by older parents often develops into a mutually caring relationship with their son or daughter as both generations age together (Carvalho, Ardore, \& Castro, 2015), at times with no need or desire for professional intervention (BILD, 2017). Other patterns of caregiving include, for example, assumed caregiving by siblings or other kin who take on primary care responsibility after parents are unable to continue or when an adult living independently declines and has no one else to look after him or her, and ascribed surrogate caregiving by non-kin, either paid or voluntary. Some of these care models mimic caregiving found in the general disability community or within the general aging population.

Given these situations, the Summit dwelt upon the issues of caregiving for people with intellectual disability affected by dementia (see Author, in press, for a fuller description of the Summit and its outputs). Thus, the aim of this article is to explore the gamut of familial or surrogate caregiving when dementia is suspected or evident, including situations beyond the conventional parental caregiver and comment on general needs in support of the caregiving. The article also posits a support-staging model of caregiving, and identifies the types of supports and services family caregivers often need to continue providing supports in the face of progressive dementia. The intent is to offer advocates, families and disability and/or dementia care providers a framework for planning and organizing supports for caregivers involved with caring for someone with an intellectual disability and dementia. A sub-aim is to provide recommendations that can guide public policy and providers when developing or providing needed family-oriented dementia care services. Our intent is not to identify dementia caregiving trends but describe the structure and relevance of varied care situations that serve to affect the well-being of adults with intellectual disability affected by dementia. In doing so, differences are acknowledged between carers of people with dementia in the population generally, typically a spouse or adult offspring, and carers of people with intellectual disability. However, we did seek international perspectives reflecting the nature of supports available to caregivers in a range of countries. Such narratives were collected by Summit participants verbally and in writing in advance of, and immediately after the International Summit 
and serve to highlight the changing role of carers post-diagnosis of dementia and as the disease progresses.

\section{Caregiving Similarities and Differences}

Studies of caregivers of persons with dementia in general can offer insights into what challenges caregivers generally face at various times and what may be their perceived needs. Ory et al. (1999) noted that caregivers of adults with dementia (compared to caregivers where dementia is not an issue) devoted more hours per week on caregiving and spent more time on supports for activities of daily living (ADL) and instrumental activities of daily living (IADL). They also found that the main service needs (as measured by services utilization) included financial planning, support group involvement, respite (at home and at program site), personal care assistance, meal assistance, home modifications, and aid with assistive devices. In a recent study of caregiving, the National Alliance for Caregiving (2017) found that most dementia-related caregivers were women in their mid-50s, usually caring for persons with dementia in their late 70s, and providing on average 28 hours of care per week. This study's findings related to needs mirrored those noted by Ory et al. (1999) in a similar study. Noted also are variations in intensity and form of caregiving that are contingent on stage. In work with people with ID, both Author et al. (2005) and McCarron et al. (2005) reported that caregiver time demands heightened in the mid-stage, over early or advanced stages, primarily due to effects of progressive cognitive impairment and adverse behaviour expression, while still being active and ambulatory.

Structural barriers may also exasperate burden as caregivers interact with and bridge health and social care providers in acquiring needed services (Taylor \& Quesnel-Vallée, 2017). With respect to caregiving focus, McCabe, You, and Tatangelo (2016) proposed two general themes that frame support needs of caregivers. The first was managing persons with dementia (e.g., meeting information and knowledge needs; support needs in managing care recipients' ADLs and IADLs, and 
behavioural and psychological symptoms of dementia (BPSD), as well as aid with formal and informal care support needs). The second theme, managing caregiver's personal needs, concerned managing caregivers' physical and psychological health, and managing caregivers' own lives.

These types of needs in general echo those of caregivers of adults with intellectual disability and dementia. However, several differentiating factors are noteworthy between these two caregiver groups (Author, 2017). One is the point when caregiving is assumed. While lifelong caregiving of a relative with intellectual disability by parents and siblings may be prevalent, later life spousal or adult offspring caregiving is more typical in the general population. The support models employed primarily tend toward 'care partners' and 'filial caregiving'. Care partner refers to a spouse or other significant person in the life of the person with dementia who cohabits or maintains a close relationship with that person. Filial caregiving refers to adult children or other relatives assuming primary care responsibilities (National Academies of Sciences, Engineering, and Medicine, 2016; National Research Summit, 2017a). A second is duration of caregiving and transitioning to a focus on dementia care. Long-term, committed caregivers who had decided early on to look after their relative with an intellectual disability often still show that same commitment when faced with the onset and ongoing progression of dementia (Author, 2010). A third is the point at which significant change in function occurs. Given the high rate of early-onset dementia among adults with Down syndrome, caregivers of such persons are often noting changes much earlier in the lifespan than among other adults affected by dementia (Jamieson-Craig et al., 2010).

Dealing with the progression of dementia involves continually adapting care to address new challenges, and these often relate to increased time demands addressing a range of new needs, and expanding caregiving responsibilities. For example, with the former, studies show that caregiving time increases significantly when persons with intellectual disability begin to show symptoms of dementia (McCarron, Gill, Lawlor, \& Begley, 2002), and that as time demands increase further in mid-stage and advanced dementia, there is also a shift in task focus (Author, 2011; McCarron, Gill, 
McCallion, \& Begley, 2005). The type of caregiving changes as adults with dementia lose functional abilities and transition from an ambulatory to non-ambulatory state. Care issues related to BPSD also arise and caregivers often find themselves having to manage restlessness and continence issues, adapting their communication, and dealing with emerging issues, such as wandering (Prasher \& Flier, 1995).

Various trends or patterns have been observed about what family caregivers need the most help with when coping with dementia care. Objective needs noted include information on signs and symptoms, diagnostic advice, help with understanding behavioural changes and managing dementia related behaviour, adapting homes, determining daily routines that would be most conducive to calming, planning for future care, and responding to end-of-life needs (Carling-Jenkins, Torr, Iacono, \& Bigby, 2012; Llewellyn, 2011; McCarron et al., 2010; Author, 1999). Author (2015) noted subjective needs of families that include: (a) wanting information especially at time of diagnosis, (b) experiencing a profound sense of loss with further diagnosis, (c) fearing the future (including financial fears), (d) having difficulty formulating long term plans, (e) struggling when accessing community-based coordinated care, (f) facing difficulties partnering with the medical community, (g) feeling overwhelmed by demands of caregiving, (h) having a sense of isolation and abandonment, and (i) having to face end-of-life issues.

\section{Family/Caregiver and Dementia Designs}

The International Summit on Intellectual Disability and Dementia considered the variety of caregiving situations and changing family caregiver needs and requirements at different stages of dementia - something rarely considered in relation to people with intellectual disability. Dementia stage-related care is commonly used within the general population (e.g., Karlsson et al., 2015) and its application has been noted in the intellectual disability field for paid caregivers with a focus on dementia presentations (e.g., Author, 1996; Author, 2013). However, the literature is 


\section{sparse on the distinction of life-span caregiving and transitioning endemic in the intellectual} disability field and has not parsed particular aspects of this type of caregiving (see Author 2017). To help with defining this, the Summit proposed a support-staging model for dementia caregiving, particular to intellectual disability, that is composed of two fundamental aspects. The first aspect is recognition of the role and nature of the involvement in caregiving, which can be either primary or secondary. While familial caregiving with people who have an intellectual disability is often lifelong, primary caregiving may be characterized by direct care/support responsibilities when persons affected by dementia either live with their caregivers or are otherwise under their direct supervision and personal care. Secondary (supportive) caregiving, on the other hand, occurs when the person lives elsewhere, separately from the family caregiver, and care does not necessarily include direct interaction, but may be more focused on advocacy, oversight, and planning. The second aspect is the influence of staging. Dementia caregiving may see caregivers move back and forth between the phases of the support-staging model as they strive to address issues that arise with the progression of dementia. It may also involve different family members at different times. Overall, staging as a process may have a variety of expressions and can be broken down further: (1) the 'diagnostic phase', seeking validation as to the cause of change in function early on with an assessment for dementia as well as later with the onset of other causes that change behaviour; (2) the 'explorative phase', accepting the diagnosis and exploring support options as it applies to the dementia diagnosis as well as additional conditions that arise; (3) the 'adaptive phase', managing the symptoms of dementia; and (4) the 'closure phase', resolving caregiving issues and relief from responsibilities following end-of-life (where 'decompression' occurs) or adapting to the loss and rebuilding lives and focus (where 'reconstruction' occurs) - depending on the degree or nature of interpersonal investment of the caregivers (See Table 1).

Insert Table 1 approximately here 
Within this model, age-associated decline or the first indications of dementia may cause caregivers to be challenged by the increasingly diminishing capacities of their relative, and having to reorient their focus. Caregiving at home may result in additional daily tasks and adjustment of various long held routines. Out-of-home caregiving may call upon new supports and skills to advocate, monitor, and seek out services - all related to identifying and addressing care for people with dementia. Dependent upon individual circumstances, in either situation, the progression of dementia will impose new demands and post-diagnostic supports will take on prominence - at least in countries with organized dementia support services (Author, 2017).

To gain a better understanding of what family caregivers face when confronted with new care demands resulting from dementia, we organized a range of narratives drawn from a variety of countries with service systems ranging from fundamental to comprehensive and framed them within our support-staging model. We believe that this structure will help in conveying what families face in times of change and how both internal and external factors may affect caregiving relationships and caregiving strategies. Caregiving takes on various forms and caregivers may be defined by roles and responsibilities assumed or ascribed to them. Thus, we use the term 'caregiver' quite broadly reflecting the range of different contexts globally and the situations in which people with intellectual disability live; demonstrating our aim to explore caregiving roles in the widest sense, and helping synthesize caregiver needs. The term 'dementia' is also used in the general sense, without attribution to type or etiology.

\section{Family Circumstances and Narratives}

The narratives used in this article were derived from brief descriptions of caregiving situations known to Summit participants, or directly from family carers themselves, and chosen for inclusion as exemplary of a variety of caregiving situations. Extensive case information was provided and then condensed for presentation in this article on key variables when available (i.e., 
situation of the person with intellectual disability, history of care, primary caregiver relationship, and outcome of progressive neuropathology). We identified the countries to offer a context for what may be the extant formal or informal services environment; however, we do not elaborate on these structures as that is not the focus of this article. The countries ranged from those with minimal to highly complex public services for intellectual disability supports (see Mercier et al., 2008). Table 2 provides a summary of seven family stories that highlight various caregiving situations and caregiver needs. Included in the table is a listing of presumptive needs and goals, positing typical needs emanating from the situations described in the narratives and offering goals for assistance in optimal situations.

Insert Table 2 approximately here

The caregiving narratives include: (a) a mother co-residing with her daughter with dementia in Scotland; (b) parent caregivers residing with their son with an unknown degenerative condition in Peru; (c) parents overseeing the out-of-home care of their son with dementia in the United States; (d) parents living separately from their son who receives formal support services in Norway; (e) sibling caregivers (sisters) of a man with early stage dementia in Brazil; (f) a sister and her husband with caregiver responsibilities for a brother with dementia in Italy; and (g) a non-kin surrogate-familial caregiver situation of a woman with dementia in the Czech Republic. Pseudonyms are used to refer to all individuals in the narratives. The narratives, as told, vary in their description, yet most focus on the events and needs as related to the persons requiring support rather than on the caregivers and their needs. As each narrative is reviewed (see Table 2), the diversity of caregiver challenges and issues become evident. The caregiver circumstances are related to the proposed support-staging model.

In narrative \#1 (pensioner mother co-residing with daughter, with multiple caregiving responsibilities; Scotland), Heather's family situation exemplifies, within our model, a typical role of 
an older-aged primary caregiver who is responsible for a daughter affected by dementia with diagnostic certainty. Further, this caregiver had dual caregiving responsibilities and lived in a rural location where access to supports is often a challenge. Relocation, another challenge, faced by the caregiver will require the mother and daughter to adjust to different routines and demands during the transition. The caregiver is adapting to ever changing needs posed by progressive dementia (the adaptive phase) and seeking out more viable post-diagnostic supports. She is also grieving the death of her husband (the closure phase).

Narrative \#2, of middle-aged parent caregivers of a younger age adult in Peru, exemplifies the situation of many parent caregivers, who live with their offspring at home, see them mature, and are then vexed by the onset of symptoms of an idiopathic neuropathology and the uncertainty as to what will happen next. Within our model, the parents are conventional primary caregivers, but are unsure of what they are facing. Given the lack of clear causal determination of the behaviour, they are in the diagnostic phase, uncertain of the reason for the behavioural change as well as seeking help in dealing with their son's behaviour - thus, also straddling the explorative phase.

This next family situation, \#3 (elderly parents overseeing the out-of-home care of their son in the United States), exemplifies within our model the transitioning from the role of primary caregivers with an adult son at home, to supportive caregivers overseeing his care in a multi-bed facility. Their search for appropriate services to meet his needs seems futile. The narrative also illustrates the extent to which family caregivers will go to continue supporting their relative in spite of a lack of needed services. In terms of the supportive-staging model, the parents are at once in the adaptive phase (monitoring behaviour and service provided as well as adjusting to a new circumstance) and in the closure phase (experiencing grief and loss, and confronting end of life care). 
In the next narrative (\#4: parents overseeing the care of their son in Norway), the parents have lived separately from Eirik, their son with an intellectual disability for years, although they remain involved and made regular visits until recently. The parents were responding to his needs, even when his primary care was provided via a formalized care structure, which began to exert greater influence in managing their son's life. Within our supportive-staging model, the situation exemplifies supportive caregivers overseeing as much as possible the supports and future care of their adult son provided by a community agency. The narrative suggests parents who have moved from the diagnostic phase to the explorative phase, considering support options. With the planned educational opportunity, they will be in a good position to advocate for and promote the development of community living options for their son as dementia progresses.

In narrative \#5 (sisters as primary caregivers for their brother), two sisters supported their brother for over 20 years since the death of their parents; first living separately, and then in the same household. This Brazilian family situation exemplifies, within our model, a transition from a supportive caregiver role to a role as active primary caregivers on the part of the sisters, who have assumed day-to-day responsibilities for his care. They recently noted several behavioral changes and are awaiting assessment results, typifying the diagnostic phase at this point. The sisters, however, are also expressing concerns about the future, and whether their brother will be able to continue to live with them, signalling the explorative phase.

This Italian family narrative, \#6 (sibling and her spouse as caregivers), exemplifies, within our model, the shifting of a sister's role over time in providing care to her brother Paolo following the death of their parents. Initially, she and her husband assumed a primary caregiver role, then transitioned to supportive caregivers when active support from an agency was required. They then took on the primary role again when the sister's brother could again co-reside with them. This family situation also serves as an example of movement between the stages of our model diagnostic (e.g., Paolo's initial misdiagnosis and then reassessment), explorative (e.g., seeking 
special care unit service), adaptive (e.g., remaining at home once unable to work), and closure (relief from responsibilities for a period of time and resolution of issues).

The last caregiver situation (\#7, surrogate familial secondary caregiver) in the Czech Republic exemplifies, within our model, the assumption of the role of supportive caregiver for a woman without any known family. Katarina, the caregiver, and Marketa were not biologically related yet had a significant relationship that was family-like in many aspects. Like others, nontraditional caregivers require recognition and support to continue their caregiving and health advocacy roles following the onset of dementia. All phases of our proposed model - diagnostic, explorative, adaptive, and closure - were experienced by Katarina over time with Marketa.

\section{Discussion}

In this article, via illustrative narratives from various countries, we explored traditional and non-traditional familial caregiving situations when dementia may be suspected or is evident. Some are co-resident and some non-co-resident. We do not purport that these illustrative narratives cover all caregiving situations, but suggest some degree of universality in that they do draw from both conventional parental/relative care-at-home situations and some atypical non-resident caregiving situations. Such caregivers, often engaged over a significant part of the lifetimes, face new challenges in supporting adults with intellectual disability when they become affected by progressive neuropathologies, such as dementia. Others flow in-and-out of engagement, but have a long-term tie to the adult.

Each of these narratives represents a variation on caregiving, some direct and some indirect, but the commonality is the engagement of the caregivers and their constant involvement and attention to the care needs of the adults with intellectual disability affected by dementia. Each reflects a shift from their previous caring role prior to diagnosis. The examples represent varied situations with at times some variance from one another with respect to how countries structure and 
provide services for dependent populations. From these narratives, we can see that these caregivers' needs correspond in most part with those cross-cutting themes we identified in the Introduction, such as: information and education about dementia, ideas about how to provide day-to-day care, adapting the physical environment for risk reduction and making care easier, coping with BPSD, seeking out medical advice, quality care, general advocacy, planning for span of care anticipated, and self-care strategies to maintain own health and well-being. Yet, we would posit that each caregiving situation is unique (even if some commonalities may be present) and thus, any supports proffered need to be tailored to each caregiver's situation and needs.

Further, we would suggest that this support-staging model of caregiving can help identify idiosyncratic needs of caregivers, irrespective of the caregiving situation. The model can help define how each situation involving dementia can individually affect the caregiver. It recognizes that needs will range from gaining an understanding of why behavior is changing, to supporting a shift in caregiving functions to accommodate dementia, to managing self-care and resiliency on the part of the caregiver, to planning for long-term care, to accommodating advanced dementia, and to getting closure, managing grief, and finding relief from caregiving. In most instances, acknowledging the demands of each stage of dementia can help define what the caregivers are facing (and what they may face) and what adaptations they may need - with a great deal of latitude for individual situations. Knowing to what degree caregivers are in involved in providing supports can also help in defining what needs they may have and how they can best be addressed.

We see this exploration of caregiving schemes as a start to better understand the situations in which caregivers find themselves and what may be their lived experiences. The narratives and the support-staging model have implications for research, policy and practice. We suggest that future research should help flesh out many of the factors we identified, test more fully our proposed support-staging model, and contribute to shaping public policy when it comes to supporting 
caregivers of adults with intellectual disability affected by dementia. Action on the following recommendations will likely have positive impact on family caregivers.

\section{Recommendations}

1. Caregivers living with or separately from their relative with intellectual disability affected by dementia should receive support and encouragement to continue their caregiver roles.

2. Effective supports offered to address family caregivers needs, such as psychoeducational sessions, planning and advocacy strategies, management of changes experienced by their relative with intellectual disability and dementia, respite, and grief and loss counselling including aid with reconstruction should be timely, appropriate, and tailored to the individual family's culture, values, beliefs, and circumstances.

3. Caregivers of persons with intellectual disability should be involved and consulted when agencies are providing dementia care.

4. Caregivers of persons with intellectual disability should be offered assistance with navigating, negotiating, and coordinating needed services from various health and social services sources.

5. Caregivers of persons with intellectual disability should be offered information on self-care strategies to minimize stress and other negative effects that long-term caregiving can or may have on physical, emotional, and mental health.

6. Research needs to be undertaken into the nuances of various family caregivers' roles and responsibilities at different stages of dementia among persons with intellectual disability to translate the findings into tailored and need-related support services. 
Perspectives on caregiving and dementia

\section{References}

BILD. (2017). Supporting older families. Accessed from: http://www.bild.org.uk/resources/ageingwell/olderfamilies/

Braddock, D., Hemp, R., \& Rizzolo, M. C. (2011). State of the states in developmental disabilities: 2004. Mental Retardation, 42(5), 356-370. Accessed from http://doi.org/10.1352/00476765(2004)42<356:SOTSID >2.0.CO;2

Carling-Jenkins, R., Torr, J., Iacono, T., \& Bigby, C. (2012). Experiences of supporting people with Down syndrome and Alzheimer's disease in aged care and family environments. Journal of Intellectual and Developmental Disability, 37(1), 54-60.

Carvalho, C.L., Ardore, M. \& Castro, L.R. (2015). Family caregivers and the aging of the person with intellectual disabilities: Implications to care. Revista Kairós Gerontologia, 18(3), 333-352.

\section{Author (2017).}

Author (2017).

Author (2017).

Author (2015).

Jamieson-Craig, R., Scior, K., Chan, T., Fenton, C. and Strydom, A. (2010). Reliance on carer reports of early symptoms of dementia among adults with intellectual disabilities. Journal of Policy and Practice in Intellectual Disabilities, 7(1), 34-41.

\section{Author (2005)}

\section{Author (1996).}

Author (2011, October ).

Author (2010). 
Author (2017).

Author 2013

Karlsson, S., Bleijlevens, M., Roe, B., Saks, K., Martin, M.S., Stephan, A., Suhonen, R., Zabalegui, A., \& Hallberg, I.R., (2015). Dementia care in European countries, from the perspective of people with dementia and their caregivers. JAN: Informing Practice and Policy Worldwide through Research and Scholarship, 71(6), 1405-1416.

Llewellyn, P. (2011). The needs of people with learning disabilities who develop dementia: A literature review. Dementia: The International Journal of Social Research and Practice, 10(2), 235-247

McCabe, M., You, E., \& Tatangelo, G., (2016). Hearing their voice: a systematic review of dementia family caregivers' needs. Gerontologist, 56(5), e70-e88.

McCarron, M., Gill, M., Lawlor, B., \& Begley, C. (2002). Time spent caregiving for persons with the dual disability of Down's syndrome and Alzheimer's dementia: Preliminary findings. Journal of Learning Disabilities, 6(3), 263-279.

McCarron, M., Gill, M., Mccallion, P., Begley, C. (2005). Alzheimer's dementia in persons with Down's syndrome: predicting time spent on day-to-day caregiving. Dementia: The International Journal of Social Research and Practice, 4(4), 521-538.

McCarron, M., McCallion, P., Fahey-McCarthy, E., Connaire, K., \& Dunn-Lane, J. (2010). Supporting persons with Down syndrome and advanced dementia: Challenges and care concerns. Dementia: The International Journal of Social Research and Practice, 9, 285-298.

Mercier, C., Saxena, S., Lecomte, J., Garrido, M., \& Harnois, G., (2008). WHO atlas on global resources for persons with intellectual disabilities 2007: Key findings relevant for low- and middle-income countries. Journal of Policy \& Practice in Intellectual Disabilities, 5(2), 81-88. 
DOI: $10.1111 / \mathrm{j} .1741-1130.2008 .00152 . x$

National Academies of Sciences, Engineering, and Medicine. (2016). Family caregiving roles and impact. In Schulz, R. \& Eden, J. (Eds)., Families caring for an aging America (pp. 73-122). Washington, DC: The National Academies Press. doi: 10.17226/23606.

National Alliance for Caregiving \& the Alzheimer's Association (2017). Dementia caregiving in the U.S. Accessed from http://www.caregiving.org/wpcontent/uploads/2017/02/DementiaCaregivingFINAL_WEB.pdf

National Research Summit on Care Services, and Supports for Persons with Dementia and Their Caregivers. (2017). Dementia caregiving in the United States. Accessed from https://aspe.hhs.gov/system/files/pdf/258151/Hunt-Day1.pdf

Ory, M.G., Hoffman, R.R., Yee, J.L., Tennstedt, S., \& Schulz, R. (1999). Prevalence and impact of caregiving: A detailed comparison between dementia and nondementia caregivers. Gerontologist, 39(2). 177-185.

Prasher V.P., \& Flier, A. (1995). Behavioral disturbance in people with Down's syndrome and dementia. Journal of Intellectual Disability Research, 39, 432-436.

Author (1999).

Taylor, M. G., \& Quesnel-Vallée, A. (2017). The structural burden of caregiving: Shared challenges in the United States and Canada. Gerontologist, 57(1), 19-25. doi: 10.1093/geront/gnw102

Tøssebro, J., Bonfils, I. S., Teittinen, A., Tideman, M., Traustadóttir, R. and Vesala, H. T. (2012). Normalization fifty years beyond - Current trends in the Nordic countries. Journal of Policy and Practice in Intellectual Disabilities, 9, 134-146. doi:10.1111/j.1741-1130.2012.00340.x

World Health Organization, \& Alzheimer's Disease International. (2012). Dementia: A public health priority. Geneve. Retrieved from http://www.who.int/mental_health/ 
Perspectives on caregiving and dementia

publications/dementia_report_2012 
Table 1: Support-Staging Model of Family-based Dementia Caregiving in Intellectual Disability

\begin{tabular}{|c|c|c|}
\hline Dementia Support Stage & Carer Factors and Supports & Outcomes/Goals \\
\hline $\begin{array}{l}\text { (1) Diagnostic Phase (seeking } \\
\text { validation of the cause of } \\
\text { change in behaviour and or } \\
\text { abilities) }\end{array}$ & $\begin{array}{l}\text { - Conferring or seeking help } \\
\text { in understanding changes } \\
\text { in behaviour and function } \\
\text { - Seeking diagnostic source } \\
\text { and following through on } \\
\text { diagnostic requirements }\end{array}$ & $\begin{array}{l}\text { - } \text { Validating suspicions } \\
\text { - } \quad \text { Tracking behaviour and } \\
\text { function } \\
\text { - Engagement in assessment } \\
\text { - } \text { and diagnostic process } \\
\text { - Obtaining a diagnosis }\end{array}$ \\
\hline $\begin{array}{l}\text { (2) Explorative Phase } \\
\text { (accepting the diagnosis and } \\
\text { considering support options) }\end{array}$ & 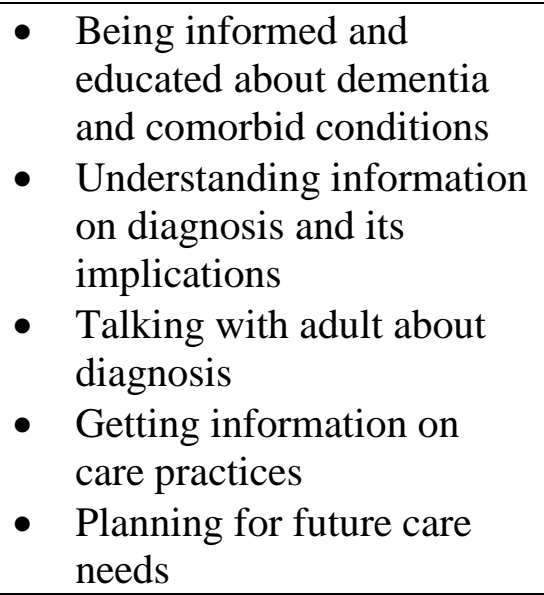 & $\begin{array}{l}\text { Better understanding of } \\
\text { disease and its progressive } \\
\text { nature. } \\
\text { - } \begin{array}{l}\text { Plan of care formulated } \\
\text { with persons affected }\end{array} \\
\text { - Alternative living } \\
\text { arrangements identified in } \\
\text { event needed } \\
\text { - Advanced care directives } \\
\text { identified } \\
\text { - Treatment decisions }\end{array}$ \\
\hline $\begin{array}{l}\text { (3) Adaptive Phase ( managing } \\
\text { symptoms of dementia) }\end{array}$ & $\begin{array}{l}\text { - } \begin{array}{l}\text { Monitoring behaviour and } \\
\text { function }\end{array} \\
\text { - Adapting care practices to } \\
\text { changes in behavior and } \\
\text { function } \\
\text { - Getting ongoing advice for } \\
\text { supports and home } \\
\text { modifications } \\
\text { - Self-care strategies } \\
\text { - Psychosocial counselling } \\
\text { including grief and loss }\end{array}$ & $\begin{array}{l}\text { - Home modifications made } \\
\text { - } \quad \text { Routines and tasks adapted } \\
\text { to reflect changes } \\
\text { - Service adaptations made } \\
\text { to accommodate family } \\
\text { needs } \\
\text { - Respite instituted } \\
\text { - Coping with changes } \\
\text { - } \quad \text { Better quality of life }\end{array}$ \\
\hline $\begin{array}{l}\text { (4) Closure Phase (resolving } \\
\text { caregiving issues and relief } \\
\text { from responsibilities, and } \\
\text { redefining next steps in life) }\end{array}$ & 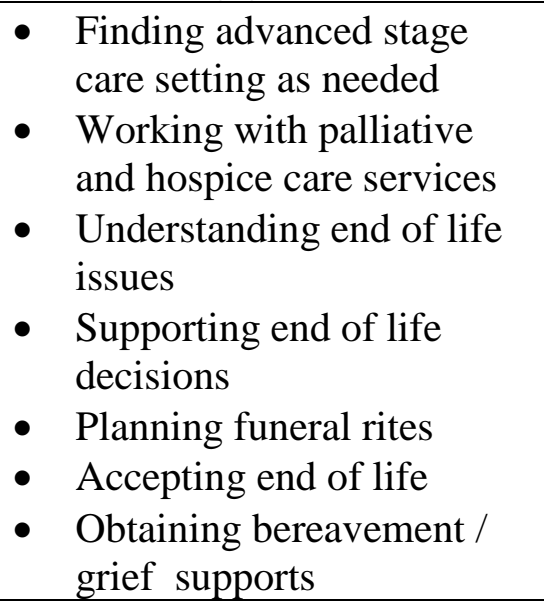 & 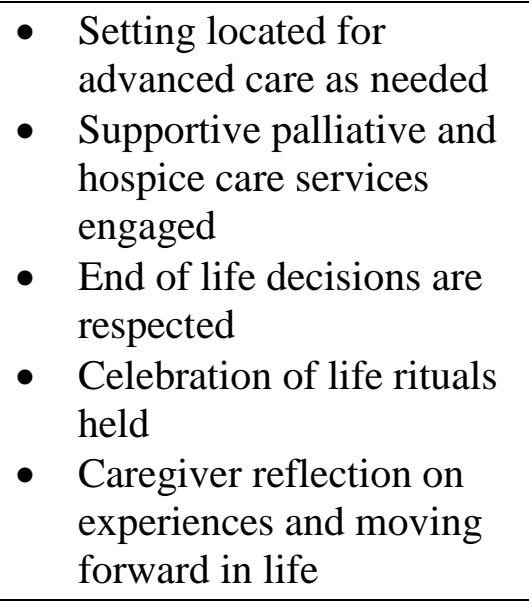 \\
\hline
\end{tabular}


Table 2: Examples of Family Circumstance, Narrative, and Presumed Caregiver Needs

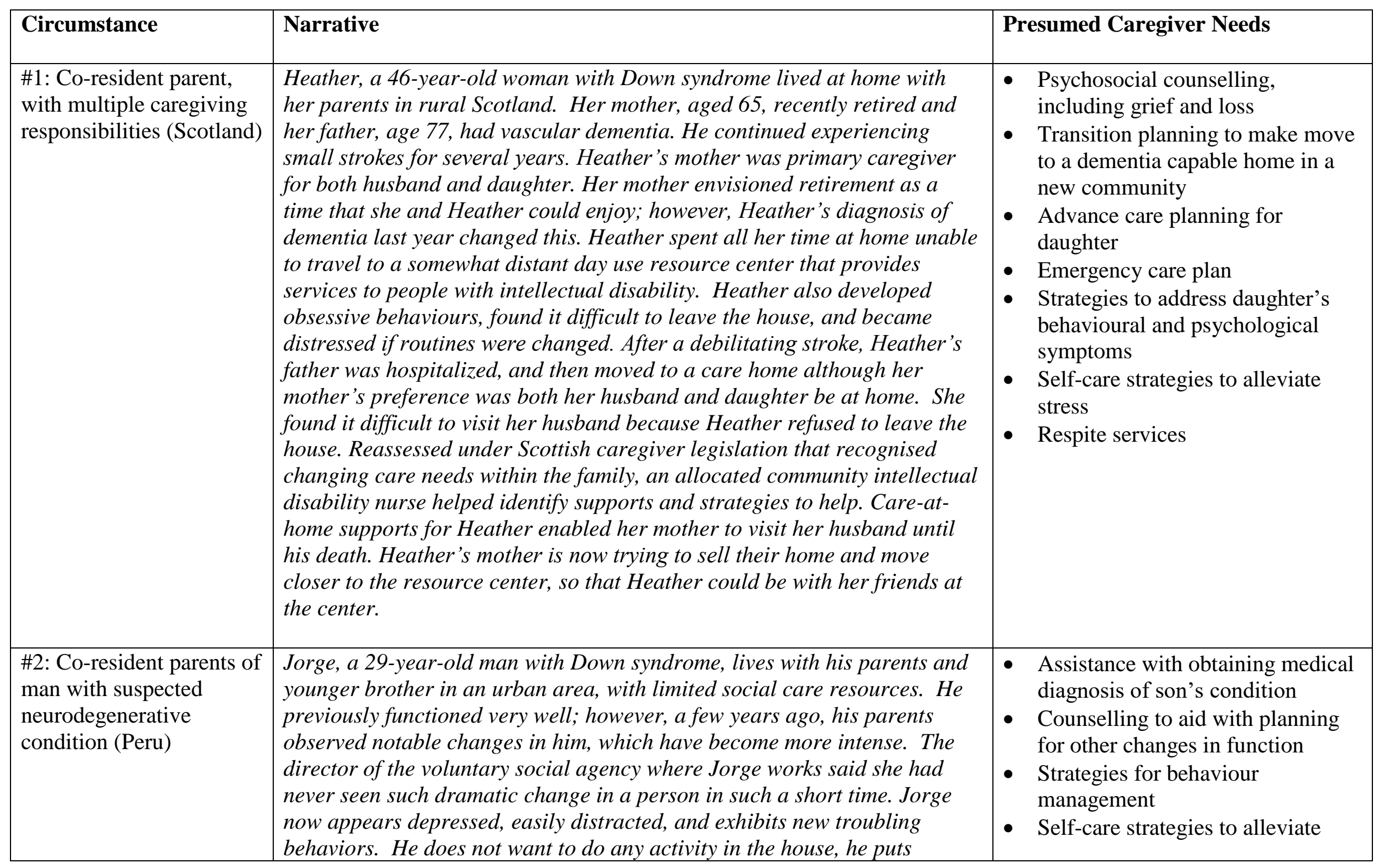




\begin{tabular}{|c|c|c|}
\hline & $\begin{array}{l}\text { clothes on backwards, quickly forgets an instruction given so he needs } \\
\text { repeated instructions to do things, is afraid of water; Jorge screams and } \\
\text { when you ask him why he says he is only "joking". He does not want to be } \\
\text { alone and speaks to himself, yet he still likes to listen to music - and } \\
\text { attends a music class. When he was age 25, the agency arranged for } \\
\text { testing, and a MRI showed normal and neurological assessments indicated } \\
\text { no abnormalities. A later assessment indicated hypothyroidism, strabismus, } \\
\text { and myopia. He was prescribed psychotropic medications, but his parents } \\
\text { took him off the medication because they did not see any changes. There is } \\
\text { a suspicion that he may have early-onset Alzheimer's disease, or } \\
\text { alternatively a regression or disintegrative disorder. The parents are } \\
\text { committed to looking after Jorge at home, but are very concerned and } \\
\text { looking for help to understand what is happening to him. }\end{array}$ & $\begin{array}{ll} & \text { stress } \\
\text { - } & \text { Respite services } \\
\text { - } & \text { Contingency planning }\end{array}$ \\
\hline $\begin{array}{l}\# 3 \text { : Parents overseeing } \\
\text { care of son, living } \\
\text { separate (USA) }\end{array}$ & $\begin{array}{l}\text { Duane's mother, aged 89, and father, aged 93, lived with their adopted son } \\
\text { who has Down syndrome in a small city in the United States. They did } \\
\text { their best to care for Duane, aged 50, at home as Alzheimer's disease } \\
\text { increasingly affected him. There was no extended family or outside } \\
\text { assistance available. Eventually Duane's parents decided to seek an } \\
\text { alternative living environment to ensure his health and safety. A group } \\
\text { home placement for Duane was offered but it was two hours from their } \\
\text { home and therefore not considered. In time, Duane was moved to a multi- } \\
\text { bed facility an hour from the family home. The facility was designed to } \\
\text { meet needs of individuals with intellectual disability and physical and or } \\
\text { mental health challenges. Staff were not specifically trained in dementia. } \\
\text { On admission, Duane was mobile and wandered around the facility. Soon } \\
\text { afterwards, he was deemed a "challenging patient" and prescribed an } \\
\text { antipsychotic medication from which he had an adverse drug reaction. His } \\
\text { parents alerted staff to the changes they saw and the medication was } \\
\text { discontinued. Within five months of admission, Duane had rapidly } \\
\text { declined. He lost ability to walk, had limited verbal or physical responses, } \\
\text { and became completely dependent on others for care. He also experienced } \\
\text { seizures more frequently requiring increased medication. Facing their }\end{array}$ & $\begin{array}{l}\text { - Support to navigate health and } \\
\text { social care to ensure quality of } \\
\text { care for their son } \\
\text { - } \quad \text { Preparing for end-of-life care } \\
\text { - Support group for caregivers with } \\
\text { similar experiences } \\
\text { - Psychosocial counselling } \\
\text { including for grief and loss } \\
\text { - Self-care strategies to alleviate } \\
\text { stress } \\
\text { - Support for parents to adjust living } \\
\text { in new community. } \\
\text { - Identifying alternative } \\
\text { transportation means with } \\
\text { diminished ability to drive }\end{array}$ \\
\hline
\end{tabular}




\begin{tabular}{|c|c|c|}
\hline & $\begin{array}{l}\text { own health changes, and determined to maintain contact with and advocate } \\
\text { for their son, Duane's parents relocated to the small town where he } \\
\text { resides. They remain ever-present and face challenges related to the } \\
\text { advanced stages of Alzheimer's disease and are deeply saddened by the } \\
\text { losses that their loving, outgoing son has experienced. }\end{array}$ & \\
\hline $\begin{array}{l}\text { \#4: Parents overseeing } \\
\text { the care of their son } \\
\text { living out-of-home } \\
\text { (Norway) }\end{array}$ & $\begin{array}{l}\text { In Norway, adults with intellectual disability often live separately from } \\
\text { their parents although typically active parental involvement and support } \\
\text { continues. Such is the situation for Eirik and his parents. Eirik's parents } \\
\text { sensed that Eirik was changing and they saw that he was becoming an old } \\
\text { man. Yet, they felt it was quite normal that he was more tired, and did not } \\
\text { want to visit as often. Dementia was far from what they had in mind. When } \\
\text { staff advised the parents that Eirik was being assessed for dementia, his } \\
\text { parent's main concern was that the authorities would move him to a } \\
\text { nursing home. They worried that for Eirik this would be like moving back } \\
\text { to an institution where he had grown up and spent his formative years. } \\
\text { Following assessment and diagnosis, Eirik's parents were relieved to hear } \\
\text { that he could continue to live in his own home for as long as possible, } \\
\text { although he would have to step down from his job. The authorities also } \\
\text { informed the parents that the eventual progression of dementia may } \\
\text { require care best be given in a nursing home; something that they wanted } \\
\text { to avoid. Eirik's parents reported that an education program for families of } \\
\text { older adults with intellectual disability has been planned by the local } \\
\text { authorities to improve knowledge about aging and dementia as well as } \\
\text { offer support and guidance to families. }\end{array}$ & $\begin{array}{l}\text { - Information on aging and the need } \\
\text { to be vigilant to changes in } \\
\text { behaviour and abilities } \\
\text { - } \text { Involvement in dementia } \\
\text { assessment process } \\
\text { - Sense of security about } \\
\text { community living options for } \\
\text { dementia care } \\
\text { - Advance care planning } \\
\text { - Support on how parents can work } \\
\text { with agency providers to secure } \\
\text { commitment for extended care in } \\
\text { community } \\
\text { - Help family collect and visualize } \\
\text { family history artifacts for use in } \\
\text { daily interactions } \\
\text { Carefully planned information and } \\
\text { education on aging and dementia } \\
\text { to ease participation }\end{array}$ \\
\hline $\begin{array}{l}\text { \#5: Siblings as caregivers } \\
\text { of their brother (Brazil) }\end{array}$ & $\begin{array}{l}\text { Jose is a man with Down syndrome who lives in the countryside of São } \\
\text { Paulo State in Brazil. He is a member of an artistic group that performs } \\
\text { voluntary dances and plays in his hometown, as well as in other Brazilian } \\
\text { states. He lived alone for almost ten years, following the death of his } \\
\text { parents, in a rented apartment paid for by his sisters. Jose had autonomy } \\
\text { and independence to do things he wanted and liked, such as to riding the } \\
\text { bus to different locations, visiting the city center, and visits at his sister's }\end{array}$ & $\begin{array}{l}\text { - Information and education on } \\
\text { dementia } \\
\text { - Means to document changes } \\
\text { noticed over time } \\
\text { - Involvement in assessment process } \\
\text { - Strategies to cope with stressful } \\
\text { interactions }\end{array}$ \\
\hline
\end{tabular}




\begin{tabular}{|c|c|c|}
\hline & $\begin{array}{l}\text { house. At around the age of } 30 \text { something changed. He was constantly } \\
\text { annoyed for no apparent reason and his mood fluctuated during the day; a } \\
\text { simple talk or gesture could be a reason for arguing. Now at age 47, Jose } \\
\text { is no longer able to live alone and lives with his sisters. His sisters have } \\
\text { observed an increase in mood swings, some hallucinations, verbal } \\
\text { aggression, and other changed behaviors. The community center team, } \\
\text { requested support from social and health care to deal with these symptoms. } \\
\text { Jose is undergoing an assessment and his sisters are concerned about the } \\
\text { future. They suspect a diagnosis of dementia and feel unprepared and ill- } \\
\text { informed of what this may mean for the family. }\end{array}$ & $\begin{array}{l}\text { - Support to develop a plan for } \\
\text { future care } \\
\text { - Support group of people with } \\
\text { similar experiences } \\
\text { - Self-care strategies to alleviate } \\
\text { stress } \\
\text { - Respite opportunities }\end{array}$ \\
\hline $\begin{array}{l}\text { \#6: Sister and husband as } \\
\text { both primary and } \\
\text { secondary caregivers } \\
\text { (Italy) }\end{array}$ & $\begin{array}{l}\text { Paolo, a 45-year man with Down syndrome, worked assembly jobs for } \\
\text { home appliance companies and lived at home. At age 40, after the death of } \\
\text { his parents, he began to reside with his sister and her husband. He began } \\
\text { repeating 'holiday', slowed down, expressed impatience at work, and } \\
\text { opposing tasks assigned to him. He also became verbally and physically } \\
\text { aggressive. Following assessment, Paolo was prescribed medications that } \\
\text { reduced behavioral problems, yet had a sedative effect on him. Eventually, } \\
\text { he was judged unsuitable for work. Years later, the family requested urgent } \\
\text { support from a special care unit (SCU) for people with intellectual } \\
\text { disability and dementia. Paolo did not speak, was obese, dependent on } \\
\text { others for daily care, and used a wheelchair. The previous dementia } \\
\text { diagnosis was reviewed and depression observed. Paolo's antipsychotic } \\
\text { drug therapy was discontinued and his behaviour and mood changed. A } \\
\text { year later, he had weekend home visits, and then, at aged 52, lived once } \\
\text { again with his sister. He attends a day center daily and occasional stays at } \\
\text { the SCU. The agency's relation with family members was a difficult path, } \\
\text { with setbacks, accusations, and discussions, but, now there is a shared } \\
\text { confidence. The family, with help, now understood that years ago, Paolo } \\
\text { was expressing his "decision" that he did not want to continue working, } \\
\text { knowing that he was changing somehow. }\end{array}$ & $\begin{array}{l}\text { Information and education on } \\
\text { changes in abilities, dementia, } \\
\text { process of assessment, including } \\
\text { rationale for a differential } \\
\text { diagnosis, and adverse drug } \\
\text { reactions } \\
\text { - Support to continue role as health } \\
\text { advocate for brother and } \\
\text { developing effective relations with } \\
\text { professionals } \\
\text { - Ongoing follow-up support to } \\
\text { monitor familial coping } \\
\text { - Continued respite opportunities. } \\
\text { - Self-care strategies to alleviate } \\
\text { caregiver stress }\end{array}$ \\
\hline
\end{tabular}




\begin{tabular}{|c|c|c|}
\hline $\begin{array}{l}\text { \#7: Surrogate family-like } \\
\text { secondary caregiver } \\
\text { (Czech Republic) }\end{array}$ & $\begin{array}{l}\text { Marketa's parents kept her after she was born, although during that time it } \\
\text { was unusual to keep a baby with a disability. Following their early deaths, } \\
\text { Marketa's brother became her primary carer before he also died suddenly. } \\
\text { At age 30, with no relatives, Marketa was admitted to a psychiatric ward } \\
\text { despite not having mental illness. In her 40s, Marketa had a new legal } \\
\text { guardian, Katarina, who arranged a transfer to a small group home. She } \\
\text { became Marketa's friend. When Katarina retired, she continued as legal } \\
\text { guardian and became a surrogate aunt. She supported Marketa } \\
\text { emotionally and organised her medical and social care. In her 50s, } \\
\text { Marketa changed; she became moody and stopped taking any initiative. } \\
\text { The group home workers became impatient, often raising their voices at } \\
\text { her. The link between dementia and some intellectual disabilities is not } \\
\text { well known in the Czech Republic, so it took some time for Katarina to } \\
\text { suspect this might be happening to Marketa. She asked a physician to } \\
\text { initiate a diagnostic process, which came back positive. Katarina hoped } \\
\text { Marketa could stay in the group home, as she was happy there. However, } \\
\text { her care needs became too much for staff and Marketa was admitted into a } \\
\text { nursing home for older people with dementia. When she died a few months } \\
\text { later, Katarina arranged a funeral and mourned Marketa as if she were a } \\
\text { niece. }\end{array}$ & $\begin{array}{l}\text { Recognition that significant others } \\
\text { also become like family and } \\
\text { assume familial roles } \\
\text { - Psychosocial counselling, } \\
\text { including grief and loss } \\
\text { - Supports to educate and inform } \\
\text { professionals and the general } \\
\text { population about dementia } \\
\text { - Supports to advocate for } \\
\text { community living options for } \\
\text { adults affected by dementia }\end{array}$ \\
\hline
\end{tabular}

